\title{
Formation of Future Foreign Language Teachers' Linguistic and Methodological Competency Using Digital Technologies
}

\author{
Olha Osova ${ }^{1}$ Tetiana Vakaliuk ${ }^{2,}{ }^{*}$ Violetta Panchenko ${ }^{1}$ Svitlana Didkivska ${ }^{3}$
}

\author{
Valerii Kontsedailo ${ }^{4}$
}

\author{
${ }^{I}$ Municipal Establishment 'Kharkiv Humanitarian Pedagogical Academy' of Kharkiv Regional Council, Ukraine \\ ${ }^{2}$ Zhytomyr Polytechnic State University, Ukraine \\ ${ }^{3}$ Cracow University of Economics, Poland \\ ${ }^{4}$ Inner Circle, Netherlands \\ *Corresponding author. Email: tetianavakaliuk@gmail.com
}

\begin{abstract}
Digital technologies greatly contribute to high-quality teacher training and the effective formation of future educators' competencies. The article aims at theoretical justification and experimental testing of the effectiveness of the formation of future foreign language teachers' linguistic and methodological competency using digital technologies. The objectives were achieved by applying a set of theoretical, empirical, and statistical methods. The experiment involved 196 students of Kharkiv Humanitarian Pedagogical Academy and H. S. Skovoroda Kharkiv National Pedagogical University. It was determined that linguistic and methodological competency included motivational-value, content-activity, and reflexive components, the effective formation of which requires application of digital tools and contributes to the intensification of communication, provides development of interactive teaching aids, delivering virtual classes.
\end{abstract}

Keywords: foreign language teacher, linguistic and methodological competency, digital technologies, competency component.

\section{INTRODUCTION}

In the current conditions of European integration and intercultural interaction, foreign languages are assuming even greater significance. Effective language learning and teaching are some of the key priorities of European language policy. The successful implementation of the strategic objectives of the Council of Europe on language policy and the principles of the Bologna Declaration in the education system of Ukraine depends on the quality of professional training of foreign language teachers, the level of their linguistic-methodological competency formation. One of the essential requirements that significantly affects the quality of professional training of future foreign language teachers, in particular the formation of their linguistic and methodological competency, is the availability of a virtual educational environment and taking into account the didactic potential of innovative methods and digital learning technologies. Consequently, it is required to develop and implement appropriate pedagogical technologies, methodologies, create an innovative communicative educational space of higher education.

Professional training of future foreign language teachers has to tackle the task of formation future specialists' linguistic-methodological competency, the complex nature of which requires the development and implementation of the newest learning technologies, including digital ones. The introduction of digital services in the process of training future foreign language teachers enhances the effectiveness of foreign language teaching, as it provides students with ample opportunities to gain unlimited access to relevant educational information and improve foreign language skills, stimulates critical thinking and creativity, promotes the development of abilities to 
solve communicative tasks in the conditions of transition from subject-object to subject-subject professional-pedagogical interaction, to choose a productive learning strategy.

Over recent years, more and more attention has been paid to the application of digital technologies in the educational process at the legislative level. The importance of applying digital technologies in professional training is stressed in the Laws of Ukraine "On Education" (2017), "On Higher Education" (2017), "National Strategy for Education in Ukraine for 2012-2021" (2012), "Concept of the new Ukrainian school" (2016), Common European Framework of Reference for Languages: Learning, Teaching, Assessment (2003), etc.

The analysis of the Ukrainian legislative framework proves that the training of a highly professional specialist who combines deep linguistic knowledge and highly developed speech skills with methodological competency, readiness to introduce innovative forms and methods in the educational process is due to the introduction of digital technologies.

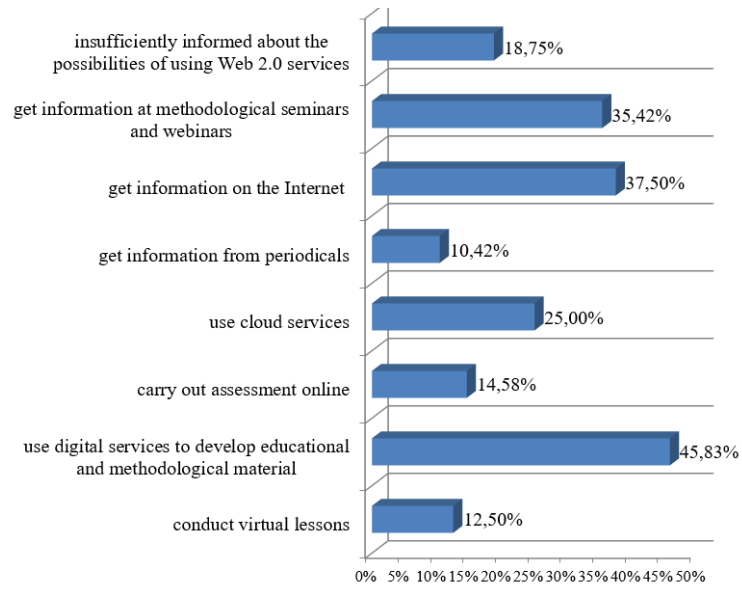

Figure 1 Results of the survey on the use of digital technologies when teaching foreign languages in Kharkiv schools.

However, the use of digital technologies in the process of foreign language learning and teaching is still accompanied by certain difficulties. Having surveyed foreign language teachers in Kharkiv (48 people), we obtained the following results: $18,75 \%$ of respondents are insufficiently informed about the possibilities of using Web 2.0 services to teach a foreign language, $35,42 \%$ get information at methodological seminars and webinars; $37,5 \%$ find it on the Internet and 10,42\% use periodicals. Moreover, foreign language teachers demonstrate a low level of awareness of digital technologies: $25 \%$ of foreign language teachers use cloud services, $14,58 \%$ carry out assessment online, $45,83 \%$ use digital services to develop educational and methodological material and $12,5 \%$ conduct virtual lessons.

Accordingly, there is a contradiction between the available didactic potential of digital services in the process of teaching foreign languages and foreign language teachers lacking the skills to use them in their professional activities. Consequently, we can claim that the problem of the formation of future foreign language teachers' linguistic and methodological competency using digital technologies is relevant and even pressing.

\subsection{Theoretical background}

Having studied theoretical works and practical experience of training future foreign language teachers, we can note that the problem of forming future foreign language teachers' linguistic and methodological competency using digital technologies is at the stage of its development. General issues of the use of digital technologies in the process of training, trends and prospects for the introduction of cloud services in the educational process, the possibility of using digital technologies in education are covered in the works by A. Alobaid [1], S. Amelina [24], V. Bykov [4], N. Bakar [3], V. Hamaniuk [24], Y. Kazhan [24], O. Kuzminska [11], M. Kyslova [11], O. Markova [12], N. Morze [11], P. Nechypurenko [14], O. Spirin [22], O. Spivakovskyi [23], M. Striuk [24], R. Tarasenko [24], V. Tkachuk [19], S. Tolmachev [24], Yu. Zaporozhchenko [26], M. Zhaldak [27], et. al. Thus, determining the pedagogical possibilities of using cloud computing when organizing education, N. Morze and N. Kuzminska mention that their use provides a personal environment for the student throughout studying, access to their environment from anywhere at any time, mobility and session saving (Hot Desking), automatic distribution of software packages in accordance with the curricula, scientific needs, etc. [11].

M. Zhaldak emphasizes the wide possibilities of using modern information and communication technologies in the educational process. He claims that their harmonious combination with the scientific and methodological achievements of the past allows secondary schools to form knowledge that underlies many modern professions related to new information and production technologies [27].

Theoretical and methodological principles of training future foreign language teachers using 
information and communication technologies have been researched by A. Aşık [2], S. Köse [2], G. Seferoğlu [2], R. Pereira [2], M. Ekiert [10], I. Kostikova [10]. I. Kostikova [10] considers information and educational environment to be one of the conditions for successful training of future foreign language teachers for professional and pedagogical activities as it gives priority to the development and implementation of information resources for educational purposes, the formation of future foreign language teachers' information culture, promotes openness of a higher education institution to international information space, assists Ukraine in gaining access to international educational space, which will contribute to enhancing the quality of education in Ukraine and its approximation to European standards [10].

The fact that the use of digital technologies in the system of professional training of future foreign language teachers significantly intensifies the educational process, leads to reconsidering traditional approaches to teaching foreign languages when training future foreign language teachers, taking into account the capabilities of digital services.

According to O. Petrichenko, the use of digital technologies improves the process of training future teachers, allows students to broaden knowledge at any time, having access to remote educational resources [18].

However, despite the undeniable value and enormous didactic potential of digital technologies in the educational environment of higher education institutions, they are not widely used in the framework of professional training of foreign language teachers and the formation of their linguistic and methodological competency.

The article aims to theoretically justify and experimentally test the effectiveness of the formation of future foreign language teachers' linguistic and methodological competency using digital technologies.

The purpose of the article is to present the experience and experimental verification of the effectiveness of the formation of linguistic and methodological competence of future foreign language teachers using digital technologies.

\section{METHODS OF RESEARCH}

To achieve the aim, a set of theoretical, empirical, and statistical research methods was used. The essence of the basic concepts of the research has been specified with the application of analysis, synthesis, comparison, classification, systematization, and generalization of scientific sources on the problem under study. Questionnaires and students' testing, interviewing teaching staff of higher education institutions, observation of methods and forms of educational interaction between teachers and students in the process of educational process organization, studying students' creative works and documentation on pedagogical practice, the pedagogical experiment made it possible to obtain results determining the levels of formation of future foreign language teachers' linguistic and methodological competency using digital technologies.

In the course of the research, methods of mathematical statistics were used to process the data obtained at the summative and control stages of the research and carry out their comparative analysis.

The experiment involved 196 students majoring in specialty 014 "Secondary Education (Language and Literature (English)", 014 "Secondary Education (Language and Literature (German)". Experimental work was conducted in the Municipal Establishment "Kharkiv Humanitarian Pedagogical Academy" of Kharkiv Regional Council and H. S. Skovoroda Kharkiv National Pedagogical University. The experimental group consisted of 99 students, the control group included 97 students. All the participants gave their written concern on taking part in the experiment.

The motivational criterion for the formation of linguistic and methodological competence of future foreign language teachers was assessed using various diagnostic techniques, content-activity - author's tests, questionnaires, personal-reflective - using a test, as well as developed portfolios.

\section{RESULTS}

Scientific reflection on the state of theory and practice of training future foreign language teachers, our own scientific and pedagogical experience have made it possible to identify linguistic and methodological competency as an important component in the structure of professional and pedagogical competency. The analysis of scientific and pedagogical sources [8] allowed us to interpret future foreign language teachers' linguistic and methodological competency as an integrative characteristic, manifested in the set of competencies in methodological and subject (foreign language) areas.

Extra attention should be paid to digital technologies that belong to effective innovative tools 
that contribute to the formation of future foreign language teachers' linguistic and methodological competency.

Experts [4], [26] claim that the most significant advantages of digital services include the possibility of conducting virtual classes, significant time and resource-saving, intensification of educational and cognitive activities, use of group sites that allow students to independently acquire knowledge and expand scientific worldview[4], [26].

In the course of the research it was found out that professional and pedagogical training of future foreign language teachers results in the formation of their linguistic and methodological competency, the components of which are motivational-value, contentactivity, and reflexive [8], [9], [16], [17].

The Motivational-value component of future foreign language teachers' linguistic and methodological competency involves forming a value attitude to the use of modern methods and technologies in foreign language teaching, stimulating interest in innovative technologies, encouraging studying didactic possibilities of innovative technologies when learning linguistic peculiarities of foreign languages. Management of future specialists' motivational sphere is carried out taking into account their individual and psychological features. It creates opportunities for balanced self-assessment of students' abilities and provides guidance in choosing the trajectory of future professional pedagogical activity using didactic possibilities of digital technologies.

The content-activity component of future foreign language teachers' linguistic and methodological competency involves knowledge about the language being studied, methods of its teaching, and appropriate skills to apply them in situations simulating future professional and pedagogical activities.

Within the reflective component of future foreign language teachers' linguistic and methodological competency, we single out students' attitudes to their professional and pedagogical activities, their realization of the results obtained after application of their teaching aids, self-control, and self-assessment of linguistic and methodological knowledge and skills, self-realization when teaching foreign languages with the use of digital technologies, etc.

All components are closely interrelated and are treated as parts of a holistic system, the functioning of which determines the effectiveness of the formation of future foreign language teachers' linguistic and methodological competency.
On the grounds of level approach [20], we determined the levels of formation of future foreign languages teachers' linguistic and methodological competency in accordance with identified criteria and indicators: high, medium, and low.

At the beginning of the research, we used questionnaires and surveys, as well as an adapted methodology for revealing communicative and organizational abilities by B. Fedoryshyn and V. Synyavsky to determine the level of formation of future foreign language teachers' linguistic and methodological competency. It was revealed that the majority of respondents had a low level $(35.9 \%$ of students) of the formation of linguistic and methodological competency, the medium level was demonstrated by $35.3 \%, 21.3 \%$ had a sufficient level and only $7.5 \%$ of respondents were at a high level, which testified to the need to test the effectiveness of the formation of future foreign language teachers' linguistic and methodological competency using digital technologies.

Consequently, at the beginning of the research, it was necessary to form students' stable motivation to use digital technologies in foreign language learning and teaching, the need to master the latest foreign language teaching technologies, to ensure positive emotions, aspirations, and lasting interests in getting the hang of digital technologies in foreign language learning and teaching.

To accomplish these objectives, some events were held to motivate and stimulate future teachers to use the opportunities of digital technologies in learning and teaching foreign languages. It was facilitated by reflexive talks, problematic discussions such as "What innovative technologies should a modern foreign language teacher master?", "How do digital learning technologies contribute to the intensification of foreign language learning?", "What digital tools should a modern foreign language teacher be able to apply?", holding creative competitions "The best quest-quiz", "The best educational portfolio", etc.

Furthermore, the need to use digital technologies for effective foreign language teaching was purposefully formed in the framework of the special course "Innovative approaches to teaching foreign languages in high school". The lessons were focused on expanding students' comprehension of innovative technologies in foreign language teaching, in particular, stimulating interest in digital technologies by getting acquainted with the best-advanced achievements in this field, etc. The content of the course included the following topics: "The essence of digital technologies. Didactic possibilities of digital 
technologies in foreign language teaching" (4 hours), "Web 2.0 technologies in the modern information society and their opportunities for learning a foreign language" (6 hours), "Introduction of cloud technologies in the educational process" ( 2 hours), etc. This course covered 150 hours, 46 of which were lectures; 14 - practical classes, 90 - students' individual work.

It was followed by the formation of the knowledge base about language and methods of its teaching with the use of digital technologies, as well as the formation of speech skills and skills to use digital services when teaching a foreign language. At this stage future foreign language teachers were offered such methods and forms of work with the use of digital services as completing tasks with the help of the Online Test Pad application (Fig. 2).

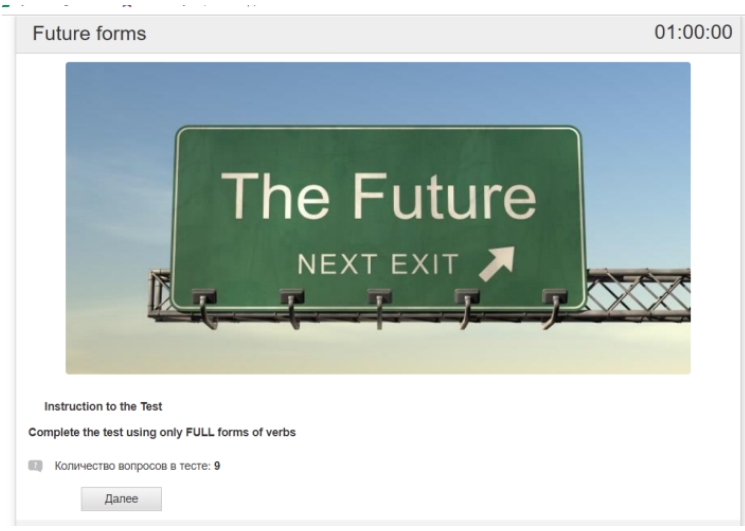

Figure 2 Interface of Online Test Pad Homepage (Grammar topic "Future Tenses").

The tasks were aimed at forming and broadening students' theoretical knowledge of the rules on using future tense forms in English, and at developing practical skills to use grammatical constructions by completing a range of various tasks on matching, filling in the gaps, finding synonymous/antonymous expressions, etc.

During the course "Methodology of teaching foreign languages in secondary education institutions" students were introduced to a variety of digital technologies and their opportunities for effective foreign language teaching. Thus, in practical classes, students were asked to create their video clips with audio and text elements, followed by questions and tasks using Edpuzzle (Fig. 3). Using the video content, students created an interactive quiz with open questions or multiple choice questions, provided oral comments and explanations to the video, or completely voiced it.
These kinds of exercises helped students acquire practical skills on working with digital services and train foreign language skills in a specific learning and speaking situation. Language learners demonstrated speech activity when doing interactive tasks, analyzed and summarized the information obtained from reference sources; gained specific technical knowledge and skills to work with digital services handy for their future professional and pedagogical activities.

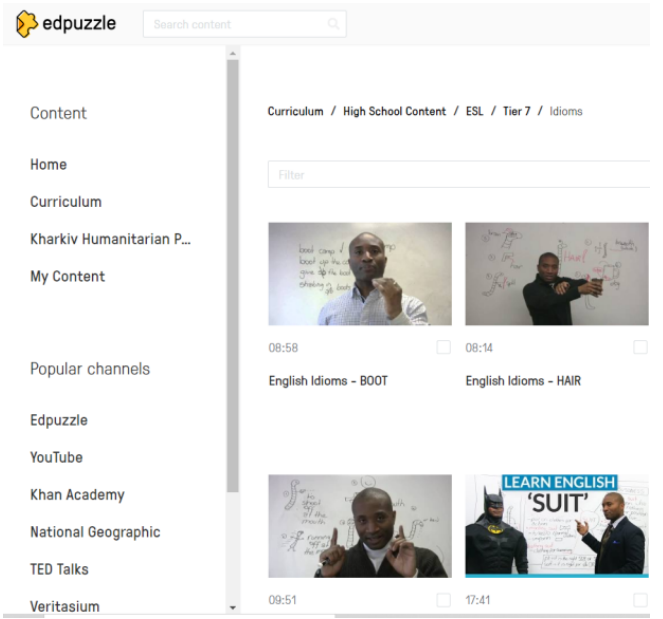

Figure 3 Edpuzzle Interface.

High-quality training of future foreign language teachers in the current conditions of educational and social development requires students to operate and absorb large amounts of information. Padlet virtual online board (padlet.com/osova_olga/ig32lehcft9j) was used as a digital platform for posting educational information, in particular, to present foreign language materials of various kinds, graphics, schemes illustrating and explaining grammatical or syntactic phenomena, multimedia files required for the formation of phonetic skills and abilities, links to Internet pages with important country study information, etc. (Fig. 4). Also, this digital service was used to present the results of the students' project work.

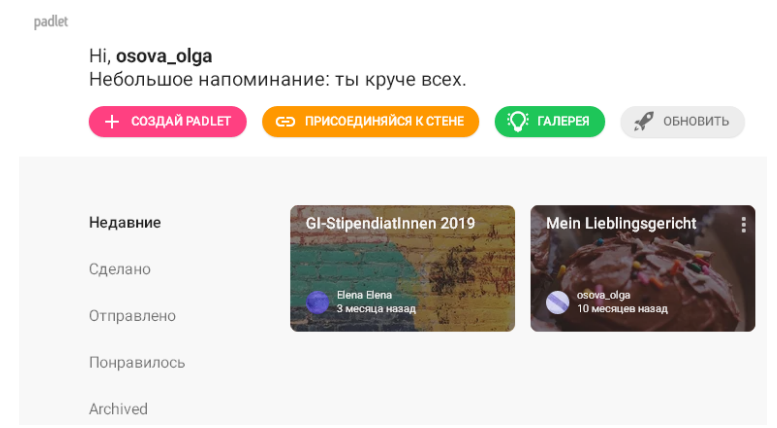

Figure 4 Interface of Padlet virtual onlineboard. 
In the framework of the special course "Innovative approaches to teaching foreign languages in high school" students were asked to develop their practical activities using the Padlet online board, which contributed to the formation of their linguistic and methodological competency using digital technologies. We should stress that completing such tasks students familiarized themselves with the possibilities of this digital service for learning a foreign language, demonstrated creativity, and trained practical skills on its application in situations simulating their future professional and pedagogical activities.

The analysis of the available digital services has shown that the Voki animated platform gives a wide range of didactic opportunities for the formation of future foreign language teachers' linguistic and methodological competency. It allows you to create animated avatars and voice them.

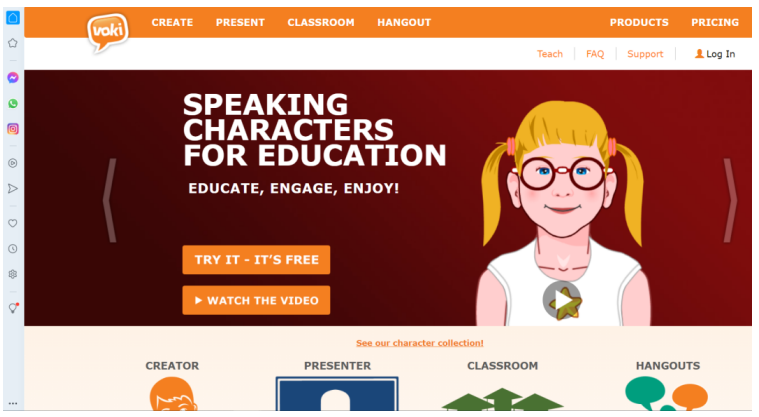

Figure 5 Interface of Voki animated platform.

For example, the technique of creating avatars was used when teaching Business Foreign Language. Students were asked to create an avatar of the school headmaster during a job interview. Students worked on creating avatars, thought of correct questions, voiced them as a part of their home assignment. During the lesson, students worked in pairs and took turns training to answer the questions of the created avatars. This activity contributed not only to the formation of foreign language listening skills, practicing functional vocabulary and specific grammatical constructions, but also developing relevant skills of professional business etiquette, as well as skills on working with digital service. One more example of the Voki-based tasks was creating avatars of students' favorite literary (fairy-tale) characters, who told the story of their lives in short monologues (10-15 sentences). This project enjoyed great popularity among students and significantly contributed to the development of their creativity. Among the most popular avatar characters created by students were Harry Potter, Frankenstein, Cinderella, etc. (http://tinyurl.com/yyew7oke). These types of tasks contributed not only to the training of lexical, grammatical, and phonetic material but also to the formation of skills to identify the essentials, analyze, synthesize, focus on details, developed rhetorical skills, etc.

Other digital resources that proved to be effective for the formation of future foreign language teachers' linguistic and communicative competency include Google Classroom, Moodle, Skype, Wiki, Zoom, YouTube, etc.

The next stage of the formation of future foreign language teachers' linguistic and methodological competency using digital technologies was aimed at the formation of self-control skills and abilities, selfassessment of proficiency level in digital technology application when learning and teaching foreign languages as well as developing skills to take a creative approach to choosing and using digital services in the future professional pedagogical activity.

At this stage, students' e-portfolios were used as means to achieve the set objectives since they are considered to be one of the indicators of a modern teacher's innovative competency and creativity. Students created their electronic portfolios with the help of the tilda.ws website designer, (http://boikoeng.tilda.ws, http://projekt1866846.tilda.ws/, http://taranina.tilda.ws/taraninalearning, etc.). They included the following sections: general information, scientific and methodological activities, achievements, etc.

Designing one's e-portfolio and filling it with the content required the ability to analyze, summarize, correctly use the appropriate speech structures, as the work was performed in a foreign language, as well as the ability to evaluate and self-evaluate one's achievements. This service allowed future foreign language teachers to analyze their achievements in a more detailed way and systematize them demonstrate foreign linguistic knowledge, self-presentation communicative skills, and the skills to use them in their future professional and pedagogical activities, the level of digital technology proficiency, to clarify issues, which needed refinement, etc. On the grounds of the aforesaid, we can claim that this resource is an effective tool for the formation of future foreign language teachers' linguistic and methodological competency.

To test the pedagogical expediency of the formation of future foreign language teachers' linguistic and methodological competency using 
digital technologies, the levels of its formation were measured. The dynamics of the formation levels of future foreign language teachers' linguistic and methodological competency using digital technologies in the experimental (EG) and control groups (CG) are presented in Figure 6.

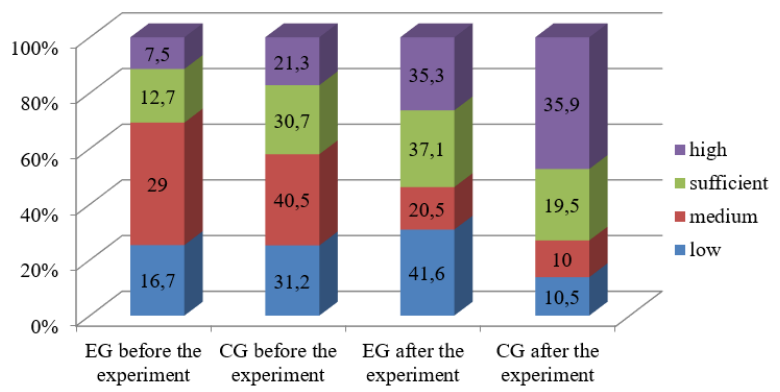

Figure 6 The summarized results of measuring levels of future foreign language teachers' linguistic and methodological competency by tools of digital technologies.

The conducted statistical calculations allowed us to establish that the percentage of students with a low level of formation of linguistic and methodological competency decreased significantly from $35.9 \%$ to $10.0 \%$ in the experimental group. The decrease in the number of students with a medium level from $35.3 \%$ to $20.5 \%$ was also observed. Instead, we notified the increase of the number of students with high and sufficient levels of formation of future foreign language teachers' linguistic and methodological competency, from $7.5 \%$ to $29.0 \%$ and from $21.3 \%$ to $40.5 \%$ respectively.

The obtained calculation results allowed us to state that the level of formation of linguistic and methodological competency using digital technologies for experimental group students is statistically significant, which is verified by calculating Student's t-test. Thus, the pedagogical experiment confirmed that the use of digital technologies is effective for the formation of future foreign language teachers' linguistic and methodological competency.

\section{CONCLUSIONS}

Thus, the conducted research makes it possible to state that the problem of using digital technologies in the process of future foreign language teacher professional training is one of the most topical and insufficiently researched ones.

It is found out that professional pedagogical training of future foreign language teachers results in the formation of their linguistic and methodological competency, which includes motivational-value, content-activity, and reflexive components. Digital services provide ample opportunities for the formation of future foreign language teachers' linguistic and methodological competency. Their application contributes to the intensification of foreign language communication, provides the development of interactive teaching aids, makes it possible to deliver virtual classes, etc.

The conducted research allows us to claim that the integration of digital technologies in professional training of future foreign language teachers stimulates cognitive interest and motivation to master the specialty using digital services, enhances students' learning outcomes in foreign language linguistics and methodology of teaching foreign languages. Having applied the method of mathematical calculations, we proved the effectiveness of the formation of future foreign language teachers' linguistic and methodological competency using digital technologies.

Speaking about the prospects for further studies, it should be noted that researchers are required to develop didactic support for linguistic disciplines with the application of digital technologies in the professional training of future foreign language teachers.

\section{REFERENCES}

[1] A. Alobaid, Smart multimedia learning of ICT: role and impact on language learners' writing fluency - YouTube online English learning resources as an example, Smart Learning Environments 7, 24 (2020). DOI: https://doi.org/10.1186/s40561-020-00134-7

[2] A. Aşık, S. Köse, G. Ekşi, G. Seferoğlu, R. Pereira, M. Ekiert, ICT integration in English language teacher education: insights from Turkey, Portugal and Poland, Computer Assisted Language Learning 33(7) (2019) 708-731. DOI: https://doi.org/10.1080/09588221.2019.1588744

[3] N.A. Bakar, H. Latif, A. Yaacob, Fusion of Technology with Language Learning: Blog Community, 3L: Language, Linguistic, Literature: The Southeast Asian Journal of English Language Studies 23(4) (2017) 200-211. DOI: http://doi.org/10.17576/3L-2017-2304-15

[4] V. Bykov, Technologies of cloud computing, ICT-outsourcing and new functions of ICTdepartments of educational and scientific institutions, Information Technologies in Education 10 (2011). 
[5] T. Chetverykova, Possibilities of applying cloud technologies in future professional activity of pedagogical college students, Scientific Bulletin of Mykolaiv V.O. Sukhomlynskyi National University. Pedagogical Sciences 1 (52) (2016) 303-307.

[6] L. Dostovalova, P. Lomasko, A. Maschanov, E. Nazarenko, A. Simonova, Teaching in a Continuously and Dynamically Changing Digital Information and Learning Environment of a Modern University, The New Educational Review $58 \quad$ (2018) 126-141. DOI: https://doi.org/10.15804/tner.2018.53.3.11.

[7] L. Holubnycha, I. Kostikova, H. Kravchenko, V. Simonok, H. Serheieva, Cloud Computing for University Students' Language Learning. Revista Romaneasca Pentru Educatie Multidimensionala 11(4) (2019) 55-69. DOI: https://doi.org/10.18662/rrem/157.

[8] I. Khyzhniak, Criterial-level structure of future primary school teachers' readiness to use electronic linguometodics tools in professional activities, Information Technologies and Learning Tools, 69(1) (2019) 160-173.

[9] O. Kopus, Theoretical and methodological foundations for forming linguistic and didactic competency of future Masters in Philology, Doctoral Dissertation, South Ukrainian National Pedagogical University named after K. D. Ushynsky, 2013.

[10] I. Kostikova, Information and communication technologies in students' language learning, International Journal of Education and Science, 1(1-2) (2018) 7-14. DOI: https://doi.org/10.26697/ijes.2018.1-2.01.

[11] M.A. Kyslova, S.O. Semerikov, K.I. Slovak, Development of mobile learning environment as a problem of the theory and methods of use of information and communication technologies in education, Information Technologies and Learning Tools 42(4) (2014) 1-19. DOI: https://doi.org/10.33407/itlt.v42i4.1104

[12] O.M. Markova, S.O. Semerikov, A.M. Striuk, The cloud technologies of learning: origin, Information Technologies and Learning Tools 46(2) (2015) 29-44. DOI: https://doi.org/10.33407/itlt.v46i2.1234

[13] N. Morze, O. Kuzminska, Pedagogical aspects of cloud computing, Information Technologies in.
Education 9 (2011) 20-29. DOI: https://doi.org/10.14308/ite000238

[14]P.P. Nechypurenko, S.O. Semerikov, T.V. Selivanova, T.O. Shenayeva, Information and communication tools for pupils' research competence formation at chemistry profile learning, Information Technologies and Learning Tools 56(6) (2016) 10-29. DOI: https://doi.org/10.33407/itlt.v56i6.1522

[15] S. Odainyk, Application of cloud technologies in managing secondary education institutions, New pedagogical thought 4 (88) (2016) 103-107.

[16]O. Osova, Professional and pedagogical competency: essence and scientific approaches, Pedagogical Sciences: collection of scientific papers of Kherson State University LXXVI (1) (2017) 128-133.

[17]N. Ostapenko, Theoretical and methodological foundation for forming linguistic and didactic competency of future teachers of Ukrainian language and literature, Doctoral Dissertation, Kyiv National Linguistic University, 2010.

[18] O. Petrichenko, Potential of cloud technologies in professional training of future Maths teachers, Academic Commentaries of Volodymyr Vynnychenko Central Ukrainian State Pedagogical University. Series: Pedagogical Sciences 177(2) (2019) 54-58.

[19] D.S. Shepiliev, S.O. Semerikov, Yu.V Yechkalo, V.V. Tkachuk, O.M. Markova, Ye.O. Modlo, I.S. Mintii, M.M. Mintii, T.V. Selivanova, N.K. Maksyshko, T.A. Vakaliuk, V.V. Osadchyi, R.O. Tarasenko, S.M. Amelina, A.E. Kiv, Development of career guidance quests using WebAR, Journal of Physics: Conference Series $1840 \quad$ (2021) 012028. DOI: https://doi.org/10.1088/1742-

6596/1840/1/012028

[20] V. Redko, O. Pasichnyk, Peculiarities of constructing the content of linear learning foreign languages in high professional schools of Ukraine, in: Problems of a modern textbook, Kyiv, 2012, pp. 649-662.

[21] O. Semenog, O. Semenikhina, P. Oleshko, R. Prima, O. Varava, R. Pykaliuk, Formation of Media Educational Skills of a Future Teacher in the Professional Training. Revista Romaneasca Pentru Educatie Multidimensionala 12(3) (2020) 
219-245.

DOI:

https://doi.org/10.18662/rrem/12.3/319.

[22] O. Spirin, T. Vakaliuk, Web-based learning technologies of teaching the basics of programming to future teachers of computer science, in: Proceedings of All-Ukrainian scientific and practical conference Mathematics and Computer Science in high school: modern challenges, Vinnytsia, 2017, pp. 61-65.

[23] A. Spivakovskiy, N. Kolesnikova, N. Tkachuk, I. Tkachuk, Web-environment for learning fundamentals of algorithms and programming, Control systems and machines (2008) 70-75.

[24] M.I. Striuk, S.O. Semerikov, A.M. Striuk, Mobility: a systems approach, Information Technologies and Learning Tools 49(5) (2015) 37-70.

DOI: https://doi.org/10.33407/itlt.v49i5.1263

[25] S. Tolmachev, Y. Kazhan, V. Hamaniuk, S. Amelina, R. Tarasenko, The use of mobile applications and Web 2.0 interactive tools for students' German-language lexical competence improvement, CEUR Workshop Proceedings 2643 (2020) 392-415.

[26] Y. Zaporozhchenko, CITRIX cloud solutions for teaching children with special needs in the USA, New computer technologies 13 (2015) 217-222.

[27]M. Zhaldak, System of teacher training to application of information and communication technologies in the educational process, Scientific Bulletin of National Pedagogical Dragomanov University. Series 2. Computer-based education systems 11(18) (2011) 3-16. 